\title{
Identification of Some Yeasts by Fatty Acid Profiles
}

\author{
BASSAM ALOKLAH ${ }^{1 *}$, ANWAR ALHAJALI ${ }^{2}$ and SABAH YAZIJI ${ }^{2}$ \\ ${ }^{1}$ Department of Industrial and Food Technique, National Commission for Biotechnology, Syria \\ ${ }^{2}$ Department of Food Science, Faculty of Agriculture, Damascus University, Syria
}

Submitted 8 January 2014, revised 15 August 2014, accepted 13 October 2014

\begin{abstract}
178 yeasts isolated from various foods were identified using ID32 C strip; Saccharomyces cerevisiae (47), Rhodotorula mucilaginosa (19), Candida kefyr (33), Candida krusei (37), Candida lusitaniae (28), Cndida lipolytica (14). The yeasts were harvested, saponified, derivatized, and extracted, and fatty acid analysis was performed by Gas Chromatography Mass Spectrometry. The yeast lipids contained Decanoic acid (C10:0), Luaric acid (C12:0), Myristoleic acid (C14:1), Myristic acid (C14:0), Pentadecanoic acid (C15:0), Palmitoleic acid C16:1), Pamitic acid (C16:0), Heptadecenoic acid (C17:1), Linoleic acid (C18:2), Linolenic acid (C18:3), Oleic acid (C18:1) and Stearic acid (C 18:0). The differences in the composition of these fatty acids could be used to identify the species as an accurate, efficient and relatively rapid method.
\end{abstract}

Ke y w ords: fatty acids, gas chromatography-mass spectrometer (GC-MS), identification, yeast

Yeasts are defined as microscopic unicellular fungi, which reproduce asexually by budding or fission (Suh et al., 2006). There are approximately 100 genera and 800 described species of yeasts (Kurtzman and Fell, 1998). Yeasts are known for the contamination and spoilage of foods and dairy products (Mushtaq et al., 2006). They have been used by the food industry principally for the production of ethanol and carbon dioxide, which are important to the brewing, wine distilling and baking industries, Yeasts are rich in proteins, lipids and vitamins (Kutty and Philip, 2008). Over the years, morphological, biochemical and physiological characteristics have been used to identify yeasts (Barnett et al., 1990). This conventional methodology requires the evaluation of some 60 to 90 tests, resulting in a complex (Arias et al., 2002). These systems are however laborious and at times give ambiguous results (Sebolai, 2004). Identification of yeast strains is routinely performed by time-consuming commercially available systems such as the ID $32 \mathrm{C}$ system, Vitek Biochemical Card, BBL Chromagar API 20C and the Minitek system (El Menyawi et al., 2000) (Maquelin et al., 2002). Alternatively phenotypic methods and genotypic methods developed for more accurate microbial identification PCR based methods or DNA sequencing are usually time-consuming and involve extensive sample preparation. Therefore, considerable efforts have focused on the invention of new techniques that can provide rapid, sensitive and informative characterization of microorganisms (Li et al., 2011).

Fatty acid methyl esters (FAME) analysis using gasliquid chromatography has been successfully applied to the identification of yeast species (Botha et al., 1993). Fatty acids (FAs) are a source of cellular energy and also serve as building blocks for a number of complex membrane lipids. Both fatty acids and sterols have the capacity to act as signaling molecules and to affect gene expression via upstream promoter elements (Garbarino and Sturley, 2005).

The spectrum of fatty acids in yeasts is rather simple, consisting mostly of $\mathrm{C} 16$ and $\mathrm{C} 18$ fatty acids. Cellular fatty acids (CFAs) are derived from three different sources: external supply, endogenous lipid (protein) turnover, and de novo synthesis and elongation (Tehlivets et al., 2007). Primary fatty acids, ranging from $\mathrm{C} 14$ to $\mathrm{C} 20$, have been detected in yeasts and have been used in the classification and identification of these organisms (Smitt et al., 1988). The most abundant FA species in yeast cells are Palmitoleic acid (16:1) and Oleic acid (18:1) followed by Palmitic acid (16:0), Stearic acid (18:0), with minor amounts of Myrictic acid (14:0) are also found in yeast (Tuller et al., 1999) (Chumnanpuen, 2012).

Kock et al. (1985) have published a number of papers dealing with the CFA of a large number of yeast species. A rigorously standardized experimental technique

\footnotetext{
* Corresponding author: B. Aloklah, Department of Industrial and Food Technique, National Commission for Biotechnology, Syria; e-mail: bassam78alk@gmail.com
} 
makes comparison of data for different genera and species possible. Various studies showed that fatty acid compositions were useful in distinguishing between species within a genus as seen in Candida, Kluyveromyces, Pichia, Saccharomyces and Schwanniomyces (Cottrell and Kock, 1989; Van der Walt, 1992; Brondz et al., 1989), (Brondz and Olsen, 1990; Marumo and Aoki, 1990; Moss et al., 1982). Van der Westhuizen (1993) could distinguish between other yeast genera of clinical importance namely Cryptococcus, Malassezia, Rhodotorula and Trichosporon which are all characterized by the presence of C:18:2 and C18:3 ( $\omega$ 3) FAs as opposed to Geotrichum and Kloeckera which only have C:18:2 but not C:18:3 ( $\omega 3$ ). Candida glabrata in turn, produces neither C:18:2 nor C:18:3 FAs but only C:18:1 FA (Van der Westhuizen, 1993).

Gangopadhyay et al., (1979) studied the cellular long-chain fatty acid contents of the anamorphic genera Candida, Cryptococcus and Torulopsis and obtained significant results which allowed them to differentiate between 38 isolates. Gunasekaran and Hughes (1980) examined 85 strains of Candida representing seven species. They found each species produced a distinctive fatty acid fingerprint, characterized by the presence or absence of certain fatty acids.

The use of long chain FA profiles for yeast identification is well reported (Botha and Kock 1993). Augustyn et al. (1991) demonstrated that minor fatty acids were useful for discrimination of 46 of the $50 \mathrm{Sac}$ charomyces cerevisiae strains studied. In addition, they found that it was also possible to separate S. cerevisiae according to the range of its CFA profiles. CFA profiles discriminated between various yeasts associated with wine spoilage (Malfeito-Ferreira et al., 1989). CFA analysis alone clearly distinguished Candida albicans from C. galabrata, C. holmii, C. parapsilosis, Cryptococcus albidus, Exophiala Jeanselmei, Lecythophara multabilis and S. cerevisiae (Prillinger et al., 2011). Kock et al. (1986) recommended estimation of fatty acid profiles as a reliable and rapid alternative to laboratory tests for distinguishing between species of Saccharomyces cultured under standard conditions. The aim of the present research is to evaluate the CFA profiles of yeast isolates obtained from various Syrian foods, using GC-MS as a rapid methodology to identify yeasts compared with the ID $32 \mathrm{C}$ system.

In recent years, several identification methods have been proposed as alternative ways to compare some classical yeast identification techniques. Among these methods were commercial miniaturized systems such as, ID32 C system, bioMérieux (Arias et al., 2002) which is a very effective way to identify yeast. A total number of 178 yeast strains were obtained from various food samples (sausage, yogurt, cheeses, jams, honey and juices) collected from various Syrian markets, especially from Damascus. In this study, isolates of yeasts were obtained from different foods (raw sausage, traditional prepared yogurt, white brined cheeses, canned jams, honey and pasteurized juices). Table I illustrates the total number of isolates. S. cerevisiae was predominant in jam, honey and juice whereas R. mucilaginosa, C. kefyr, C. krusei and C.lusitaniae were predominant in yogurt and cheese, but C. lipolytica was predominant in sausage. These results were in agreement with Arias et al. (2002) who studied yeasts associated with orange juice and with Mushtaq, et al. (2006) in detection of yeast micro-flora from milk and yogurt in Pakistan.

The yeasts were grown on Malt Extract Agar (MEA) medium consisting. The isolates were incubated on (MEA) at $30^{\circ} \mathrm{C}$ for $24 \mathrm{~h}$, and identified using ID $32 \mathrm{C}$ system (bioMérieux, Marcy-I’Etoile, France) which consists of 31 assimilation tests (Table II) according to manufacturer's instructions. The yeast isolates which were identified by ID 32 C system were S. cerevisiae, R. mucilaginosa, C.kefyr, C.krusei, C.lusitaniae and C. lipolytica, the results showed that a combination of tests (CEL, 2KG, MDG, RHA, SBE, PLE, GLN) are positive in C. lusitaniae, (ARA, RIB, ESC) are positive in R. mucilaginosa, LAC is positive in C. kefyr, and ERY is positive in C. lipolytica.

The isolates used for FAMEs were grown on MEA at $30^{\circ} \mathrm{C}$ for $24 \mathrm{~h}, 0.4 \mathrm{~g}$ of wet cells was harvested and transferred into a $20 \mathrm{~mL}$ glass screw-cap test tube. The

Table I

Yeast species isolated from different foods

\begin{tabular}{|l|c|c|c|c|c|c|}
\hline \multicolumn{1}{|c|}{ Food } & S. cerevisiae & R. mucilaginosa & C. kefyr & C. krusei & C. lusitaniae & C. lipolytica \\
\hline Sausage & 7 & 3 & 4 & 6 & 5 & 9 \\
\hline Yogurt & 9 & 6 & 16 & 13 & 9 & 4 \\
\hline Cheese & 6 & 5 & 10 & 11 & 8 & 1 \\
\hline Jam & 14 & 1 & 1 & - & 1 & - \\
\hline Honey & 3 & - & - & - & - & - \\
\hline Juice & 8 & 4 & 2 & 7 & 5 & - \\
\hline Total & $\mathbf{4 7}$ & $\mathbf{1 9}$ & $\mathbf{3 3}$ & $\mathbf{3 7}$ & $\mathbf{2 8}$ & $\mathbf{1 4}$ \\
\hline
\end{tabular}


Table II

Physiological diagnostic results by ID $32 \mathrm{C}$ system

\begin{tabular}{|c|c|c|c|c|c|c|}
\hline Test & S. cerevisiae & R. mucilaginosa & C. kefyr & C. krusei & C. lusitaniae & C. lipolytica \\
\hline GAL & - & + & + & - & + & - \\
\hline ACT & - & - & + & + & - & + \\
\hline SAC & + & + & + & - & + & - \\
\hline NAG & - & + & - & + & + & + \\
\hline LAT & - & - & + & + & - & + \\
\hline ARA & - & + & - & - & - & - \\
\hline CEL & - & - & - & - & + & - \\
\hline RAF & + & + & + & - & - & - \\
\hline MAL & + & + & - & - & + & - \\
\hline TRE & - & + & - & - & + & - \\
\hline $2 \mathrm{KG}$ & - & - & - & - & + & - \\
\hline MDG & - & - & - & - & + & - \\
\hline MAN & - & - & - & - & + & + \\
\hline LAC & - & - & + & - & - & - \\
\hline INO & - & - & - & - & - & - \\
\hline SOR & - & - & + & - & + & - \\
\hline XYL & - & + & + & - & - & - \\
\hline RIB & - & + & - & - & - & - \\
\hline GLY & - & + & - & - & - & + \\
\hline RHA & - & - & - & - & + & - \\
\hline PLE & - & - & - & - & + & - \\
\hline ERY & - & - & - & - & - & + \\
\hline MEL & - & - & - & - & - & - \\
\hline GRT & - & - & - & - & - & - \\
\hline MLZ & - & - & - & - & + & + \\
\hline GNT & - & - & - & - & - & - \\
\hline LVT & - & - & - & - & - & - \\
\hline GLU & + & + & + & + & + & + \\
\hline SBE & - & - & - & - & + & - \\
\hline GLN & - & - & - & - & + & - \\
\hline ESC & - & + & - & - & - & - \\
\hline
\end{tabular}

suspension was boiled for at $\mathrm{C}$ in a water bath (Memmert, Germany) to extract FA from cellular lipids and saponify them to sodium salts. The FAMEs derivatives were prepared by adding $6 \mathrm{~N} \mathrm{HCl}$ solution in methanol and heating at $80^{\circ} \mathrm{C}$. FAMEs were extracted from the aqueous phase with a hexane-methyl-tert-butyl ether reagent. A diluted solution of $\mathrm{NaOH}$ in water was used to remove residual reagents from the organic extracts, The upper solvent phase was then transferred into $2 \mathrm{ml}$ glass vials (Sasser, 2001). FAMEs analysis was performed on a GC-MS (Agilent technology 7890A, USA) with a capillary column DB- $1(30 \mathrm{~m} \times 0.25 \mathrm{~mm} \times 0.25 \mu \mathrm{m})$. The temperature was programmed from $125^{\circ} \mathrm{C}$ (held for $2 \mathrm{~min}$ ) to $150^{\circ} \mathrm{C}$ at a rate of $5^{\circ} \mathrm{C} / \mathrm{min}$, then from $150^{\circ} \mathrm{C}$ to $250^{\circ} \mathrm{C}$ at a rate of $4^{\circ} \mathrm{C} / \mathrm{min}$. The carrier gas was helium with a split ratio of 1: 50. FAMEs (C12:0,
C14:0, C15:0, C16:1, C16:0, C18:1(9), C18:1(11), C18:2, C18:0) were identified by the standard solution standard Supelco-47080-U (Sigma-Aldrich inc, Germany) and the FAMEs (C10:0, C14:1, C17:1, C18:3) were compared with NIST library in MS (Agilent 5975A, USA), with the following settings; ionization voltage $70 \mathrm{eV}$, quadrupole temperature $150^{\circ} \mathrm{C}$, ion source temperature $230^{\circ} \mathrm{C}$, scan mass range $15-450 \mathrm{amu}$.

The procedure for the determination of fatty acids by GC-MS consists of several steps such as esterification of lipids, sample injection, separation, identification and quantification (Eder, 1995). The accuracy of total fatty acids quantification is generally influenced by a number of experimental factors. Esterification of lipids is the most critical step among those. Acid-catalyzed transesterification is the most common used method 
Table III

Average percentage fatty acid composition of isolated yeasts

\begin{tabular}{|l|c|c|c|c|c|c|}
\hline Fatty acids & S. cerevisiae & R. mucilaginosa & C. kefyr & C. krusei & C. lusitaniae & C. lipolytica \\
\hline C10:0 & $6.15 \pm 1.18$ & - & $0.06 \pm 0.01$ & $0.03 \pm 0.02$ & - & - \\
\hline C12:0 & $7.59 \pm 1.35$ & - & $0.22 \pm 0.02$ & $0.04 \pm 0.01$ & $0.28 \pm 0.02$ & - \\
\hline C14:1 & $0.98 \pm 0.04$ & - & $0.24 \pm 0.05$ & - & - & - \\
\hline C14:0 & $1.90 \pm 0.05$ & $1.83 \pm 0.11$ & $2.05 \pm 0.13$ & $0.44 \pm 0.06$ & $1.06 \pm 0.04$ & - \\
\hline C15:0 & - & - & $0.25 \pm 0.06$ & $0.79 \pm 0.04$ & - & $0.87 \pm 0.11$ \\
\hline C16:1 & $51.21 \pm 2.25$ & $5.69 \pm 0.38$ & $27.46 \pm 2.48$ & $17.69 \pm 1.67$ & $10.21 \pm 1.05$ & $17.22 \pm 1.12$ \\
\hline C16:0 & $12.72 \pm 1.45$ & $17.56 \pm 1.88$ & $20.06 \pm 1.55$ & $15.26 \pm 1.55$ & $18.41 \pm 2.13$ & $11.99 \pm 2.23$ \\
\hline C17:1 & - & $0.40 \pm 0.06$ & $0.08 \pm 0.01$ & $1.65 \pm 0.18$ & - & $2.71 \pm 0.43$ \\
\hline C18:2 & - & $11.85 \pm 1.75$ & $19.41 \pm 2.13$ & $22.21 \pm 2.14$ & $33.15 \pm 2.17$ & $23.01 \pm 2.15$ \\
\hline C18:3 & - & $4.60 \pm 0.98$ & $4.01 \pm 0.66$ & $13.61 \pm 1.78$ & $9.30 \pm 1.44$ & - \\
\hline C18:1(9) & $18.50 \pm 1.33$ & $55.89 \pm 2.55$ & $24.61 \pm 2.38$ & $25.51 \pm 2.15$ & $25.66 \pm 2.33$ & $42.85 \pm 3.65$ \\
\hline C18:1(11) & - & - & $0.40 \pm 0.02$ & $1.94 \pm 0.11$ & $0.54 \pm 0.04$ & $0.58 \pm 0.04$ \\
\hline C18:0 & $0.95 \pm 0.02$ & $2.18 \pm 0.07$ & $1.15 \pm 0.04$ & $0.83 \pm 0.03$ & $1.39 \pm 0.06$ & $0.77 \pm 0.02$ \\
\hline Total \% & 100 & 100 & 100 & 100 & 100 & 100 \\
\hline SFA & 29.32 & 21.57 & 23.79 & 17.39 & 21.14 & 13.63 \\
\hline MUFA & 70.69 & 61.98 & 52.79 & 46.79 & 36.41 & 63.36 \\
\hline PUFA & - & 16.45 & 23.42 & 35.82 & 42.45 & 23.01 \\
\hline Total \% & $\mathbf{1 0 0}$ & $\mathbf{1 0 0}$ & $\mathbf{1 0 0}$ & $\mathbf{1 0 0}$ & $\mathbf{1 0 0}$ & $\mathbf{1 0 0}$ \\
\hline
\end{tabular}

for preparation of FAMEs, which is found in various applications (Khoomrung et al., 2008; Glaser et al., 2010)

FAME analysis using gas-liquid chromatography is a method widely available in microbiological laboratories and which has successfully been applied to the identification of clinically important yeast species (Kutty and Pilip, 2008).

It has been reported that long chain FAs of C16:0 and C18:0 chain lengths predominate in yeasts and include Palmitic (16:0), Palmitoleic (C16:1), Stearic (C18:0), Oleic (C18:1), Linoleic (C:8:2), Linolenic acids (C18:3) ) Prillinger et al., 2011)

Various studies have shown that some variations in the mean relative percentages of FAs present in the cellular material from different strains within the same species can occur (Kock and Botha, 1998). Thus, to obtain a representative FA profile of a particular yeast species, as many representative strains as possible must be examined.

Within genera, long-chain FA composition seems to be of more value. For instance, within Kluyveromyces, Lipomyces, Nadsonia, Rhodosporium, Saccharomyces and Schizosacchaomyces. It was possible to distinguish between a selection of species using FA composition (Prillinger et al., 2011). In the present study FAMEs were analyzed by means of GC-MS. The results revealed the existence of thirteen fatty acids in the yeasts species in this study. Table III illustrates the average FA composition of isolated yeasts in hundred percent. These fatty acids consisted of C10:0, C12:0, C14:1, C14:0, C15:0,
C16:1, C16:0, C17:1, C18:2, C18:3, C18:1(9), C18:1(11) and C18:0. The FA of yeasts species varied in composition and in quantity between them in this study.

The six species of yeasts linking at Euclidian Distance could be separated into five groups as shown in the dendogram cluster analysis based on fatty acid profiles (Fig. 1).

Saccharomyces cerevisiae had the highest content of C10:0 and C12:0 (6.15 and 7.59\%, respectively), for this reason it had the highest content of SFAs (29.23\%), and so the content of C16:1 (51.21\%), which increased the MUFAs content (70.68\%); while the PUFAs such as C18:2 and C18:3 were not detected and seem to be absent. These results were in agreement with Avery et al. (1996), who noticed that the content of C16:1 were $55.7 \%$ and Torijia et al. (2003) who found that the content of medium-chain FAs of C10:0 and C12:0 were $15.61 \%$. The absence of PUFAs was also reported by Frerreira et al. (2004) and Rozez et al. (1992) in their studies on strains of $S$. cerevisiae.

Cis-9-octadecenoic [C18:1(9)] was The predominant FA in R. mucilaginosa (55.89\%) when compared with other species, while C10:0, C12:0, C14:1, C15:0, and C18:1(11) were not detected. These results corresponded with those recorded by Schneider et al. (2013), which revealed the predominance of Palmitic (16:0) and Oleic (18:1) acids in this species.

C. kefyr contained all thirteen FAs from C10:0 to C18:0. The predominant FAs were C16:1, C18:1(9), C16:0, C18:2 (27.46\%, 24.61\%, 20.06\% and 19.41\%, 


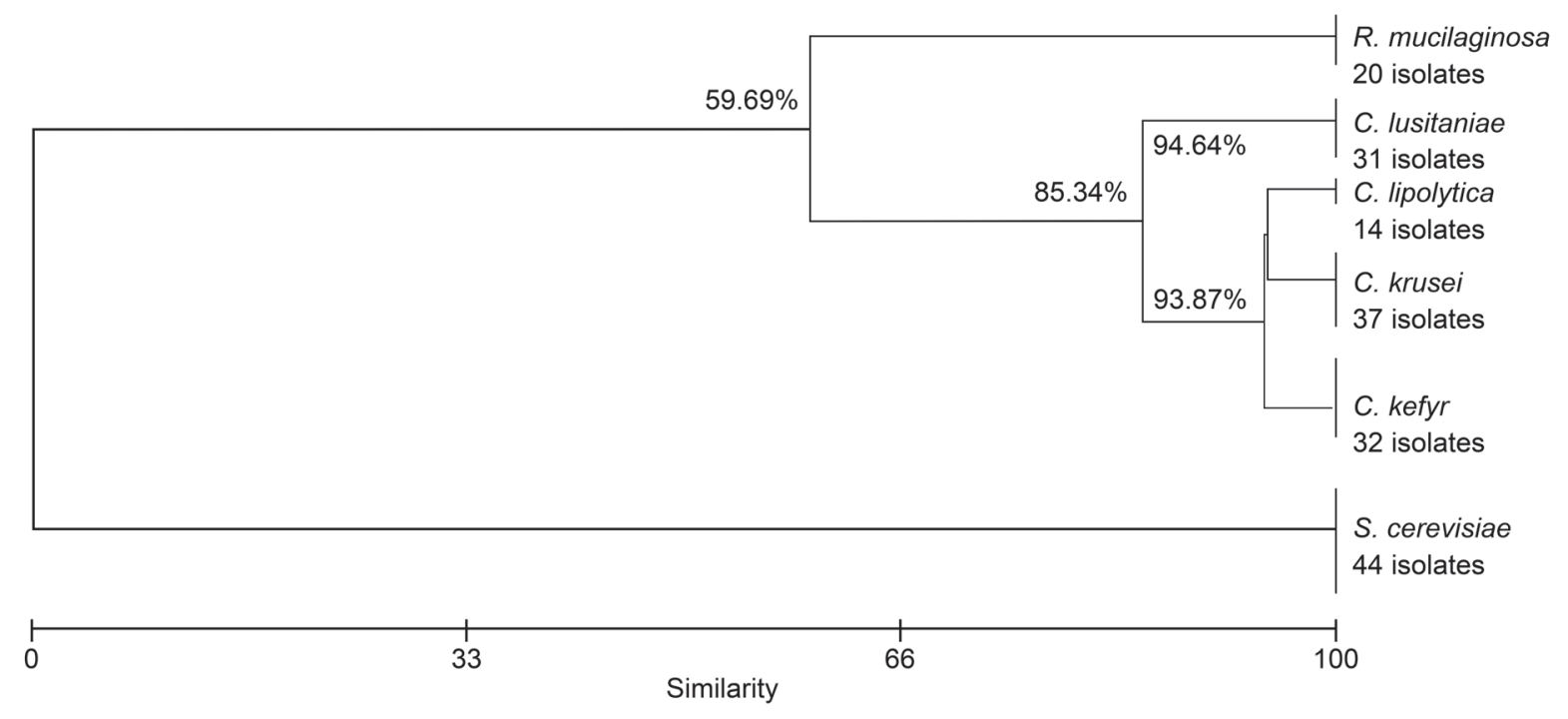

Fig. 1. Dendrogram cluster analysis based on fatty acids of yeasts

respectively). The percent of C16:1 corresponded with that found by Viljone et al. (1987) who reported that C16:1 was 27.9\%. Moreover, the SFAs and PUSFAs were almost the same (23.79\% and $23.42 \%$, respectively); this feature seems to be characterized more in this species compared with the others.

The major FAs in C. krusei were C18:1(9), C18:2, C16:1, C16:0 and C18:3 (25.51\%, 22.21\%, 17.69\%, 15.26\% and $13.61 \%$, respectively), with the highest amount of C18:3 when compared with the other yeast species in this study. This content was much higher than the value recorded by Blignaut et al. (1996) who found that the content of this FA was ranged between 5.1 and $6.3 \%$.

C. lusitiniae showed that it contained nine fatty acids with the absent of C10:0, C14:1, C15:0 and C17:1. This species was recognized by the highest content of C18:1(9) (33.15\%), that interoperates the high amount of total PUFAs (42.45\%).

The predominant FA in C. lipolytica was C18:1(9) $(42.85 \%)$.This result was in agreement with Viljone et al., (1987) who reported that the content C18:1(9) was the dominating FA in this species with o $55.89 \%$ percent. Apart from C18:1(9), the major FAs were C18:2, C16:1 and C16:0 (23.01\%, 17.22\% and 11.99\%, respectively). Both C. lipolytica and S. cerevisiae can be recognized by the absence of $\mathrm{C} 18: 3$.

In summary, fatty acids were extracted from whole yeast cells of S.cerevisiae, R.mucilaginosa, C. kefyr, C. krusei, C. lusitaniae and C.lipolytica isolated from a variety of foods (sausage, yogurt, cheeses, jams, honey and juices) and identified by ID $32 \mathrm{C}$ system and using GC-MS. The results of thde ID32 C system showed close agreement with fatty acids results.

The FAMEs were identified and quantified by using GC-MS, which is a rapid and sensitive procedure to distinguish between different species of yeasts, while the ID32 C system was accurate but expensive, laborintensive and time-consuming.

\section{Literature}

Arias C.R., J.K. Burns, L.M. Friedrich, R.M. Goodrich and M.E. Parish. 2002. Yeast Species Associated with Orange Juice: Evaluation of Different Identification Methods. Appl. Environ. Microb., pp. 1955-1961

Augustyn O.P.H., D. Ferreira and J.L.F. Kock. 1991. Differentiation between yeast species, and strains within a species, by cellular fatty acid analysis. Saccharomyces sensu stricto, Hanseniaspora, Saccharomycodes and Wickerhamiella. Syst. Appl. Microbiol. 14: 324-334. Avery S.V., N.G. Howlett and S. Radice. 1996. Copper Toxicity towards Saccharomyces cerevisiae: Dependence on Plasma Membrane Fatty Acid Composition. Appl. Environ. Microb. pp. 3960-3966.

Barnett J.A., R.W. Payne and D. Yarrow. 1990. Yeasts: Characteristics and identification, 2nd Ed. Cambridge University Press, Cambridge, pp. +10 .

Blignauti E., A.R. Senek, J.L.F. Kock, A. Botha and J.P.J.V. Westhuizen. 1996. The Value of Cellular Fatty Acid Analysis in the Identification of Oral Yeasts. System. Appl. Microbiol. 19: 381-387. Botha A. and J.L. Kock. 1993. Application of fatty acid profiles in the identification of yeasts. Int. J. Food Microbiol. 19: 39-51.

Brondz, I., I. Olsen and M. Sjostrom. 1989. Gas chromatographic assessment of alcoholyzed fatty acids from yeasts: a new chemotaxonomic method. J. Clin. Microbiol. 27, 2815-2819.

Brondz I. and L. Olsen. 1990. Multivariate analysis of cellular carbohydrates and fatty acids of Candida albicans, Torulopsis glabrata and Saccharomyces cerevisiae. J. Clin. Microbiol. 28: 18541857.

Chumnanpuen P. 2012. Systems Biology of Yeast Lipid Metabolism Chalmers University of Technology, Göteborg, Sweden. Phd thesis, pp. $2-4$.

Cottrell M. and J.L.F. Kock. 1989. The yeast Lipomycetaceae Novák et Zsolt emend. Van der Walt et al. and the genus Myxozyma Van der Walt et al. A historical account of its delimitation and the taxonomic relevance of cellular long-chain fatty acid composition and other phenotypic characters. Syst. Appl. Microbiol. 12: 291-305. 
Eder K. 1995. Gas chromatographic analysis of fatty acid methyl esters. J. Chromatogr Biomed. Appl. 671(1-2): 113-131.

El Menyawi I., M. Wögerbauer, H. Sigmund, H. Burgmann and W. Graninger. 2000. Identification of yeast species by fatty acid profiling as measured by gas-liquid chromatography. J. Chromatogr. B. Biomed. Sci. Appl. 742(1): 13-24.

Ferreira T., M. R'egnacq, P. Alimardani, C. Moreau-Vauzelle and T. Berg'es. 2004. Lipid dynamics in yeast under haem-induced unsaturated fatty acid and/or sterol depletion. Biochem. J. 378: 899-908. Gangopadhyay P.K., H. Thadepalli, I. Roy and A. Ansari. 1979. Identification of species of Candida, Cryptococcus and Torulopsis by gas-liquid chromatography. J. Inf. Diseases. 140: 952-958.

Garbarino J. and S.L. Sturley. 2005. Homeostatic systems for sterols and other lipids. Biochem. Soc. Trans. 33: 1182-1185.

Glaser C., H. Demmelmair and B. Koletzko. 2010 High-throughput analysis of total plasma fatty acid composition with direct in situ transesterification. J. Lipid Res. 51(1): 216-221.

Gunasekaran M. and W.T. Hughes. 1980. Gas-liquid chromatography: a rapid method for identification of different species of Candida. Mycologia 72(3): 505-511.

Khoomrung S., K. Laoteng, S. Jitsue and S. Cheevadhanarak. 2008. Significance of fatty acid supplementation on profiles of cell growth, fatty acid, and gene expression of three desaturases in Mucor rouxii. Appl. Microbiol. Biotechnol. 80 (3): 499-506.

Kock J.L.E, P.M. Lategan, E.J. Botes and B.C. Viljoen. 1985. Developing a rapid statistical identification process for different yeast species. J. Microbiol. Methods. 4: 147-154.

Kock J.L.F., M. Cottrell and P.M. Lategan. 1986. A rapid method to differentiate between five species of the genus Saccharomyces. Appl. Microbiol. Biotechnol. 23: 499-501.

Kock J.L.F. and A. Botha. 1998. Fatty acids in fungal taxonomy. In: Frisvad J.C., Bridge P.D., Arora D.K. (Ed.), Chemical Fungal Taxonomy Marcel Dekker, New York, pp. 219-246.

Kurtzman C.P. and J.W. Fell. 1998. The Yeasts, A Taxonomic Study, 4th Ed. Elsevier, Amsterdam, 1055.

Prillinger H., K. Lopandic, M. Suzuki, J.L.F. Kock and T. Boekhout. 2011. Chemotaxonomy of yeasts. In: The yeasts a taxonomic study Kurtzman C.P., Fell J.W. and Boekhout T., British library, London, pp. 129-137.

Kutty S.N. and R. Philip. 2008. Marine yeasts - a review, Yeast, 25: 465-483.

Li T., L. Dai, L. Li, X. Hu, L. Dong, J. Li, S.K. Salim, J. Fu and H. Zhong. 2011. Typing of unknown microorganisms based on quantitative analysis of fatty acids by mass spectrometry and hierarchical clustering. Analytica. Chimica. Acta 684: 8-16.

Libkind D., M.T. Arts and M.V. Broock. 2008. Fatty acid composition of cold-adapted carotenogenic basidiomycetous yeasts. Revista Argentina de Microbiología 40: 193-197.

Malfeito-Ferreira M., J. Lopes and V. Loureiro. 1989. Infecting yeasts in Portuguese bottled white wines. Proceedings of the XIII ${ }^{\text {th }}$ International Symposium on Yeasts. Leuven, Belgium, pp. 34- 35.
Maquelin K., L.P. Choo-Smith, H.P. Endtz, H.A. Bruining and G.J. Puppels. 2002. Rapid identification of Candida species by confocal raman microspectroscopy. J. Clin. Microbiol. 40: 594-600. Marumo K. and Y. Aoki. 1990. Discriminate analysis of cellular fatty acids of Candida species, Torulopsis glabrata and Cryptococcus neoformans determined by gas-liquid chromatography. J. Clin. Microbiol. 28: 1509-1513.

Moss C.E., T. Shinoda and J.W. Samuels. 1982. Determination of cellular fatty acid compositions of various yeasts by gas-liquid chromatography. J. Clin. Microbiol. 16: 1073-1079.

Mushtaq M., F. Iftikhar and S. Nahar. 2006. Detection of yeast micro-flora from milk and yogurt in Pakistan. Pak. J. Bot. 38(3): 859-868.

Razes N., C.G. Jares, F. Larue and A.L. Funel. 1992. Differentiation between fermenting and spoilage yeasts in wine by total free fatty acid analysis. J. Sci. Food Agric. 59: 351-351.

Sasser M. 2001. Identification of Bacteria by Gas Chromatography of Cellular Fatty Acids. Sherlock Microbial Identification System References.

Sebolai E.M. 2004. The lipid composition of the yeast genus Saccharomycopsis Schiönning. University of the Free State Bloemfontein South Africa. Master Thesis, pp. 2-126.

Smit J., J.F.L. Kock, P.J. Van Der Westhuizen and T.J. Britz. 1988. Taxonomic relationships of Cryptococcus and Tremella based on fatty acid composition and other phenotypic characters. J. Gen. Microb. 134: 2849-2855.

Suh S.O., C.P. Kurtzman and M. Lachane. 2006. Phylogenetics of Saccharomycetales, the Ascomycete yeasts. Mycologia 98:1006-1017. Tehlivet O., K. Scheuringer and S.D. Kohlwein. 2007. Fatty acid synthesis and elongation in yeast. Biochimica et Biophysica. Acta 1771: 255-270.

Torija M.J., G. Beltran, M. Novo, M. Poblet, J.M. Guillamo, A. Mas and N. Roze. 2003. Effects of fermentation temperature and Saccharomyces species on the cell fatty acid composition and presence of volatile compounds in wine. Int. J. Food Microbiol. 85: $127-136$

Tuller G.T. and E.A. Nemec. 1999. Lipid composition of sub cellular membranes of an FY1679-derived haploid yeast wild-type strain grown on different carbon sources. Yeast, 15(14): 1555-1564.

Van der Walt J.P. 1992. The Lipomycetaceae, a model family for phylogenetic studies. Ant. V., Leeuwenhoek, 62: 247-250.

Van der Westhuizen J.P.J. 1993. The distribution of w3 and w6 series of cellular long-chain fatty acids in fungi associated with disease. Ph. D., Thesis. Department of Microbiology and Biochemistry, Faculty of Science, University of the Orange Free State, Bloemfontein, Republic of South Africa.

Viljoen B.C., J.F. Kock, H.A.B. Muller and P.M. Lategan. 1987. Long-chain fatty acid compositions of some asporogenous yeasts and their respective ascosporogenous states. J. Microbiol. 133: 1019-1022. 